\title{
Renal Replacement Therapy And Increased Risk Of Cardiovascular Disease In El-Minia Governorate, Upper Egypt
}

\author{
El-Minshawy O*, and Kamel E G** \\ Departments of internal Medicine* and Public Health of Medicine**, El-Minia \\ University, El Minia, Egypt
}

\begin{abstract}
Introduction: End stage renal disease (ESRD) is one of the main health problems in El Minia Governorate Currently, hemodialysis (HD) represents the main mode for treatment of ESRD in El Minia Governorate. El Minia Governorate consists of 9 districts and total population of 4.6 millions. The aim of this study: is to describe the prevalence rate and etiology of ESRD in patients under Renal Replacement Therapy (RRT) in El Minia Governorate during the year 2005 and risk factors for cardiovascular disease in this group of patients. Material and Method: Patients of ESRD were interviewed and questionnaires were filled out by the investigators. The questionnair included personal data, past history of relevant diseases, renal biopsy results, ultrasonography, dialysis frequency, lipid profile, ECG, Echocardiography and other data investigating the cause of ESRD and the causes of death. Results: This study included 614 patients, that is $51 \%$ of the estimated total number of patients treated by RRT in El-Minia governorate. The prevalence of ESRD in El- Minia governorate is 260/ per million population (PMP). Most patients are treated by hemodialysis (HD) (97.2\%) while only $2.8 \%$ are treated by either peritoneal dialysis or renal transplantation. The etiology of ESRD was unknown in $28 \%$ of cases while hypertension was responsible for $20.7 \%$ of cases, obstructive uropathy $12.7 \%$, chronic glomerulonephritis $10.4 \%$, analgesic nephropathy $6 \%$ chronic pyelonephritis $5.8 \%$, and diabetic nephropathy $5 \%$. Other causes such as gouty nephropathy, collagen diseases, toxaemia of pregnancy and lupus nephritis constituted $7 \%$ of cases.The prevalence of ischemic heart disease was $16.5 \%$, congestive heart failure $28 \%$ Cerebrovascular accidents $5 \%$, the death rate among HD patients during this year was 210/1000. Recommendation: Education program for nephrologists and practitioners should be strengthened with special emphasis on etiological factors leading to ESRD, blood pressure control with focus on systolic pressure appears to be an important stratgey to improve outcomes in HD patients, Attempts to establish a program for renal Transplantation should be encourged.
\end{abstract}

\section{Introduction}

End stage renal disease (ESRD) is one of the main health problems in El Minia Governorate Currently, hemodialysis (HD) represents the main mode for treatment of (ESRD) in El Minia Governorate. El Minia Governorate consists of 9 districts and total population of 4.6 millions. The epidemiology of ESRD has been examined once in 2002 by ( El Minshawy et al., 2002) however there is no reliable data neither on Cardiovascular disease nor on its risk factors in El Minia Governorate hemodialysis patients.

In Egypt the prevalance of dialysis patients is presumed to have increased from
10 per million in 1974 to about 165 per million in 1995 (Afifi and Abd El Karim 1999). In the five North African countries the incidence of renal disaese is much higher than that in the west yet the prevalance is relatively lower which mirrors the adequacy of medical care facilities (Barsoum, 2003).

Despite the aggressive treatment of diabetes mellitus, hypertension and hyperlipedemia the incidence and prevalence rates of ESRD continues to increase world wide (Satko et al., 2005)

Chronic kidney disaese (CKD) is becoming an independent risk factor for 
cardiovascular disease. The American heart association recommended that patients with CKD can be considered as members of the highest risk group for subsequent cardiovascular events (Coresh et al., 2004)

Myocardial infarction and other cardiovascular events constitute the leading causes of death in dialysis dependent ESRD patients. Left ventricular hypertrophy (LVH) has been known as an independent risk factor for cariovascular death in both dialysis and general population (Kan and Yang 2004). Moreover cardiovascular diseases specially LVH are the major cause of mortality in uremic patients treated by hemodialysis. Progressive renal disease is associated with increased risk of cardiovascular death specially sudden death (Stewart et al., 2005)

One potentially modifiable risk factor for CVD in CKD is dyslipedemia but observational studies have noted that a reverse epidemiology in patients with CKD as that low total cholesterol levels are associated with higher mortality rate (Weiner and Sarnak, 2004)

\section{Aim of the work}

The aim of this study is to describe the prevalence, rate and etiology of ESRD in patients under Renal Replacement Therapy in El Minia Governorate during the year 2005 and risk factors of cardiovascular disease in this group of patients.

\section{Material and Methods}

Egypt is formed of 26 governorates, El Minia governorate is one of upper Egypt governorates. El Minia governorate is formed of 9 districts. Patients of ESRD were interviewed and questionnaires were filled by the investigators. The questionnaire included personal data, age, sex, residence, occupation, special habits and past history of relevant diseases. Renal biopsy results, ultrasonography, dialysis frequency and other data investigating the cause of ESRD as well as the causes of death were also investigated. All patients underwent complete clinical examination with special emphasis on cardiac examination. Echocardiography was used for routine analysis and assement of left ventricular hypertrophy and diastolic dysfunction. Collected data were manipulated using an IBM compatible PC and SPSS program for windows release 10 for statistical analysis.

\section{Results}

In El-Minia governorate there are 19 dialysis centers with variable capacities, some of them were reluctant to cooperate in this study and refused to allow the investigators to meet the patients. This study included 614 patients, that is $51 \%$ of the estimated total number of dialysis patients in El-Minia governorate according to the records of Ministry Health. The estimated prevalence of ESRD in El- Minia governorate at the time of the study was 260/ million polpulation per million population (PMP).

Males were more than females in this study (64\% and $36 \%$ respectively), while patients lived in the rural areas were more than those lived in urban areas $(56 \%$ and $44 \%$ respectively). The mean age of the patients was $44.6 \pm 13.7$ years, ranged from 13 to 81 years old. Furthermore, the duration of the dialysis was $60 \pm 45$ months ranged from 1-306 months and all patients were dialyzed 3 times per week.

Echocardiography revealed that $\mathrm{LVH}$ was present in $66 \%$ and diastolic dysfunction was present in $76 \%$ of patients. Plain $X$ ray chest PA view shows cardiomegaly in $30 \%$ of patients. Resting ECG was normal in $30 \%$ of patients and illustreated LVH in $37 \%$ of patients, Ischemic changes in $16.5 \%$ of patients, low voltage in $10 \%$ of patients and Arrythmia in $6.5 \%$ of patients.

The prevalence of dyslipedemia was $21 \%$ in HD patients and only $30 \%$ of them were under treatment with drug therapy.

Table (1) showes the distribution of the patients among the 9 districts of ElMinia governorate. About $44 \%$ of patients were from El-Minia city. The prevalence of ESRD showed no significant sex difference among most of districts. Females were 
more than males in El-Minia city and Samalout, while males were more than females in Bany Mazar.

The etiology of ESRD was unknown in $28 \%$ of cases while hypertension was responsible for $20.7 \%$ of cases, obstructive uropathy $12.7 \%$, Bilhazial stricture obstructive uropathy $4.4 \%$, chronic glomerulonephritis $10.4 \%$, analgesic nephropathy $6 \%$ Chronic pyelonephritis $5.8 \%$ and diabetic nephropathy 5\%. Other causes such as gouty nephropathy, collagen diseases, toxaemia of pregnancy and lupus nephritis constituted $7 \%$ of cases. The prevalence of hypertension and analgesic nephropathy was significantly higher in females than males, while the prevalence of obstructive uropathy due to schistosomiasis and those due to unknown causes were significantly higher in males than females (Table 2).

ESRD due to diabetic nephropathy was significantly higher in urban (7.8\%) than in rural areas (2.9\%), while those due to obstructive uropathy caused by schistosomiasis was significantly higher in rural (7\%) than in urban areas (1.1\%). Other causes of ESRD showed no significant differences between rural and urban areas (Table 3).

Figure (1) showes that $28.3 \%$ of patients were housewives, $23.3 \%$ were farmers, $17.4 \%$ were clerk, $17.1 \%$ had no job, while $13.8 \%$ of patients were manual workers. Table (4) reveals that hypertension, chronic pyelonephritis and analgesic nephropathy were common among housewives, while chronic glomerulonepritis, obstructive uropathy and obstructive uropathy due to schistosomiasis were common among farmers. In addition, it was found that diabetic nephropathy was common among clerk patients.

Table (1): Prevalence of ESRD among males and females in different districts of El-Minia governorate

\begin{tabular}{|l|c|c|c|c|}
\hline District & Males & Females & P & Total \\
\hline Edwa & $8(2 \%)$ & $4(1.8 \%)$ & 0.43 & $12(2 \%)$ \\
\hline Maghagha & $25(6.4 \%)$ & $8(3.6 \%)$ & 0.07 & $33(5.4 \%)$ \\
\hline Bany Mazar & $30(7.6 \%)$ & $7(3.2 \%)$ & 0.01 & $37(6 \%)$ \\
\hline Mattay & $9(2.3 \%)$ & $2(0.9 \%)$ & 0.12 & $11(1.8 \%)$ \\
\hline Samalout & $80(2.4 \%)$ & $42(19 \%)$ & 0.0001 & $122(19.9 \%)$ \\
\hline El-Minia & $150(38.2 \%)$ & $120(54.3 \%)$ & 0.0001 & $270(44 \%)$ \\
\hline Abou Korkas & $27(6.9 \%)$ & $10(4.5 \%)$ & 0.11 & $37(6 \%)$ \\
\hline Malawy & $38(9.7 \%)$ & $17(7.7 \%)$ & 0.20 & $55(9 \%)$ \\
\hline Deir Mawas & $26(6.6 \%)$ & $11(5 \%)$ & 0.21 & $37(6 \%)$ \\
\hline Total & $393(100 \%)$ & $221(100 \%)$ & - & $614(100)$ \\
\hline
\end{tabular}

Table (2): Comparison between males and females regarding the etiology of the ESRD

\begin{tabular}{|l|c|c|c|c|}
\hline Etiology & Males & Females & P & Total \\
\hline Hypertension & $69(17.6 \%)$ & $58(26.2 \%)$ & 0.005 & $127(20.7 \%)$ \\
\hline Pyelonephritis & $21(5.3 \%)$ & $14(6.3 \%)$ & 0.32 & $35(5.7 \%)$ \\
\hline Glomerulonephritis & $44(11.2 \%)$ & $20(9 \%)$ & 0.21 & $64(10.4 \%)$ \\
\hline Diabetic nephropathy & $18(4.6 \%)$ & $13(5.9 \%)$ & 0.24 & $31(5 \%)$ \\
\hline Schistosomiasis & $25(6.4 \%)$ & $2(0.9 \%)$ & 0.001 & $27(4.4 \%)$ \\
\hline Obstructive uropathy & $52(13.2 \%)$ & $26(11.8 \%)$ & 0.33 & $78(12.7 \%)$ \\
\hline Analgesic nephropathy & $19(4.8 \%)$ & $18(8.1 \%)$ & 0.04 & $37(6 \%)$ \\
\hline Others & $17(4.3 \%)$ & $26(11.8 \%)$ & 0.005 & $43(7 \%)$ \\
\hline Unknown & $128(32.6 \%)$ & $44(19.9 \%)$ & 0.001 & $172(28 \%)$ \\
\hline Total & $393(100 \%)$ & $221(100 \%)$ & - & $614(100)$ \\
\hline
\end{tabular}


Table (3): Comparison between rural and urban areas regarding the etiology of the ESRD

\begin{tabular}{|l|c|c|c|c|}
\hline Etiology & Rural & Urban & P & Total \\
\hline Hypertension & $65(18.9 \%)$ & $62(23 \%)$ & 0.13 & $127(20.7 \%)$ \\
\hline Pyelonephritis & $19(\% 5.5)$ & $16(5.9 \%)$ & 0.41 & $35(5.7 \%)$ \\
\hline Glomerulonephritis & $31(9 \%)$ & $33(12.2 \%)$ & 0.11 & $64(10.4 \%)$ \\
\hline Diabetic nephropathy & $10(2.9 \%)$ & $21(7.8 \%)$ & 0.002 & $31(5 \%)$ \\
\hline Schistosomiasis & $24(7 \%)$ & $3(1.1 \%)$ & 0.001 & $27(4.4 \%)$ \\
\hline Obstructive uropathy & $49(14.2 \%)$ & $29(10.7 \%)$ & 0.10 & $78(12.7 \%)$ \\
\hline Analgesic nephropathy & $19(5.5 \%)$ & $18(6.7 \%)$ & 0.27 & $37(6 \%)$ \\
\hline Others & $14(4.1 \%)$ & $29(10.7 \%)$ & 0.001 & $43(7 \%)$ \\
\hline Unknown & $113(32.8 \%)$ & $59(21.9 \%)$ & 0.001 & $172(28 \%)$ \\
\hline Total & $344(100 \%)$ & $270(100 \%)$ & - & $614(100)$ \\
\hline
\end{tabular}

Table 4: Relationship between etiology of ESRD and occupation of the patients

\begin{tabular}{|l|c|c|c|c|c|c|}
\hline Etiology & Farmer & Clerk & No job & Housewife & Manual & Total \\
\hline Hypertension & 26 & 16 & 20 & 47 & 18 & 127 \\
& $(20.5 \%)$ & $(12.6 \%)$ & $(15.8 \%)$ & $(37 \%)$ & $(14.2 \%)$ & $(100 \%)$ \\
\hline Pyelonephritis & 6 & 6 & 7 & 11 & 5 & 35 \\
& $(17.1 \%)$ & $(17.1 \%)$ & $(20 \%)$ & $(31.4 \%)$ & $(14.3 \%)$ & $(100 \%)$ \\
\hline Glomerulonephritis & 16 & 13 & 9 & 12 & 14 & 64 \\
& $(25 \%)$ & $(20.3 \%)$ & $(14.1 \%)$ & $(18.8 \%)$ & $(21.9 \%)$ & $(100 \%)$ \\
\hline Diabetic nephropathy & 4 & 12 & 0 & 11 & 4 & 31 \\
& $(12.9 \%)$ & $(38.7 \%)$ & $(0 \%)$ & $(35.5 \%)$ & $(12.9 \%)$ & $(100 \%)$ \\
\hline Schistosomiasis & 11 & 4 & 5 & 2 & 5 & 27 \\
& $(40.7 \%)$ & $(14.8 \%)$ & $(18.5 \%)$ & $(7.4 \%)$ & $(18.5 \%)$ & $(100 \%)$ \\
\hline Obstructive uropathy & 24 & 8 & 16 & 20 & 10 & 78 \\
& $(30.8 \%)$ & $(10.3 \%)$ & $(20.5 \%)$ & $(25.6 \%)$ & $(12.8 \%)$ & $(100 \%)$ \\
\hline Analgesic Nephropathy & $9(24.3 \%)$ & 4 & 2 & 14 & 8 & 37 \\
& & $(10.8 \%)$ & $(5.4 \%)$ & $(37.8 \%)$ & $(21.6 \%)$ & $(100 \%)$ \\
\hline Others & 2 & 8 & 7 & 21 & 5 & 43 \\
& $(4.7 \%)$ & $(18.6 \%)$ & $(16.3 \%)$ & $(48.8 \%)$ & $(11.6 \%)$ & $(100 \%)$ \\
\hline Unknown & 45 & 36 & 39 & 36 & 16 & 172 \\
& $(26.2 \%)$ & $(20.9 \%)$ & $(22.6 \%)$ & $(20.9 \%)$ & $(9.3 \%)$ & $(100 \%)$ \\
\hline Total & 143 & 107 & 105 & 174 & 8.5 & 614 \\
& $(23.3 \%)$ & $(17.4 \%)$ & $(17.1 \%)$ & $(28.3 \%)$ & $(13.8 \%)$ & $(100 \%)$ \\
\hline
\end{tabular}

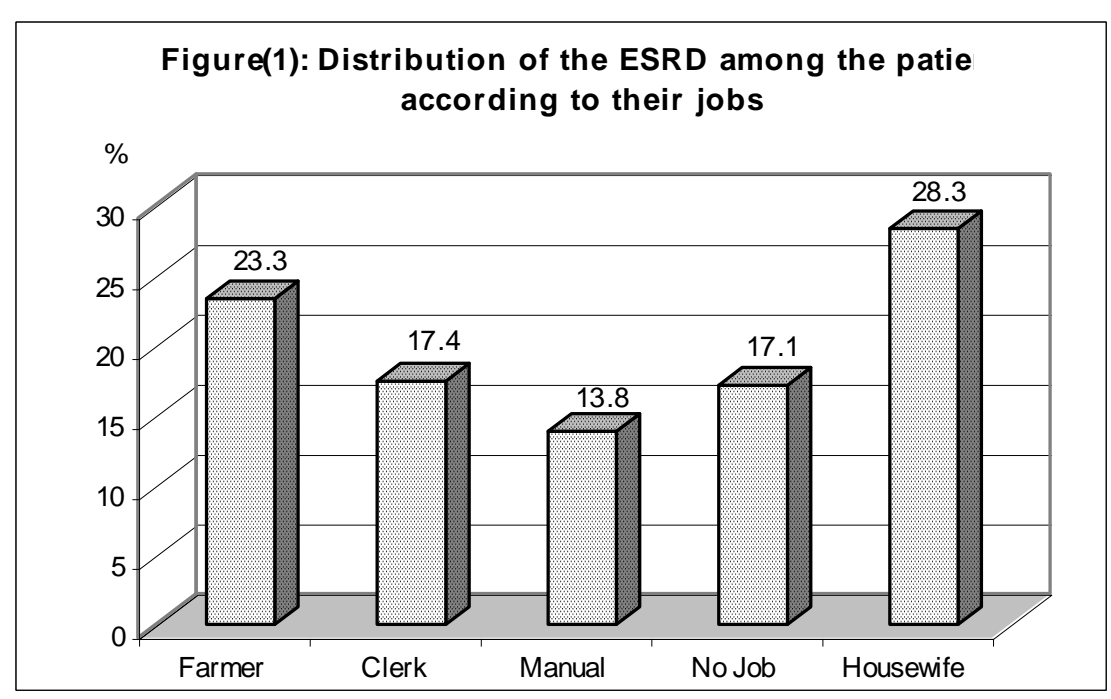


Figure 2: Prevalence of dyslipedemia in patients with ESRD

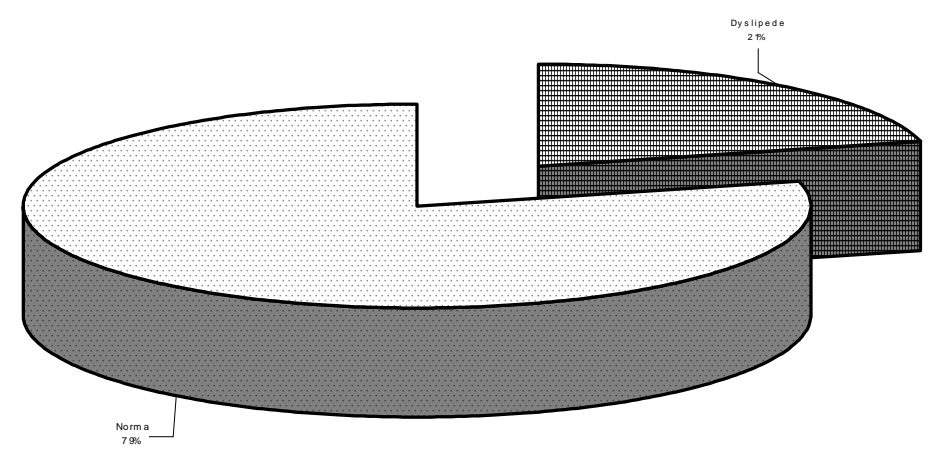

Figure 3: Resting ECG finding among patients with ESRD

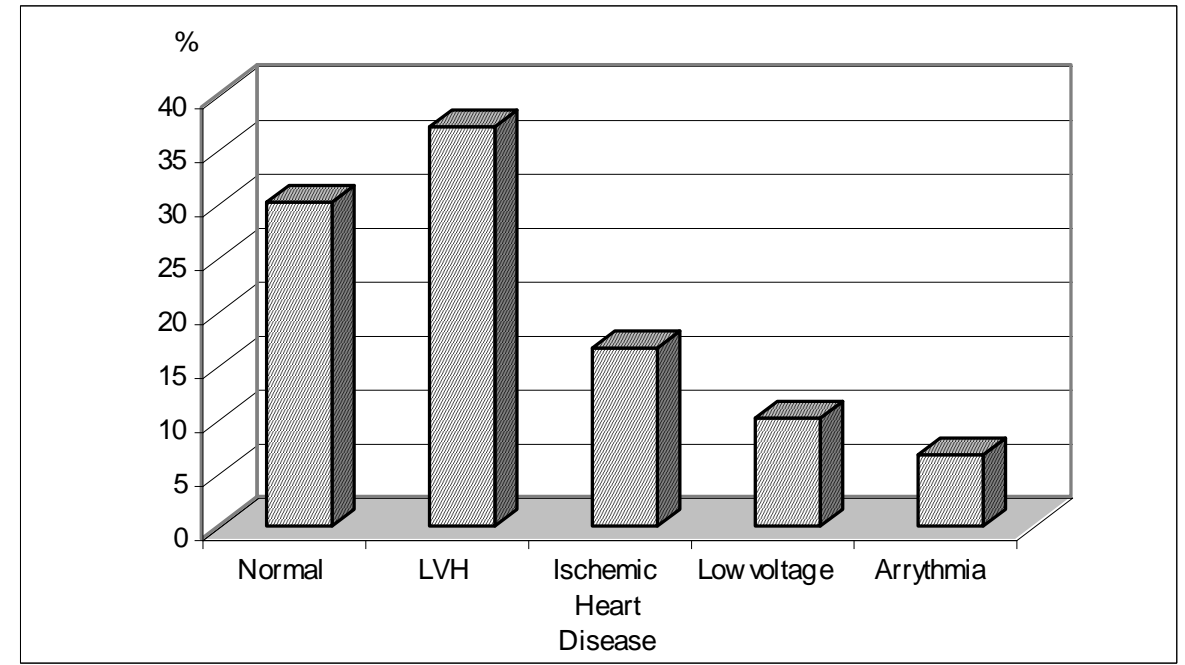

Figure 4: Echocardiographic findings among patients with ESRD

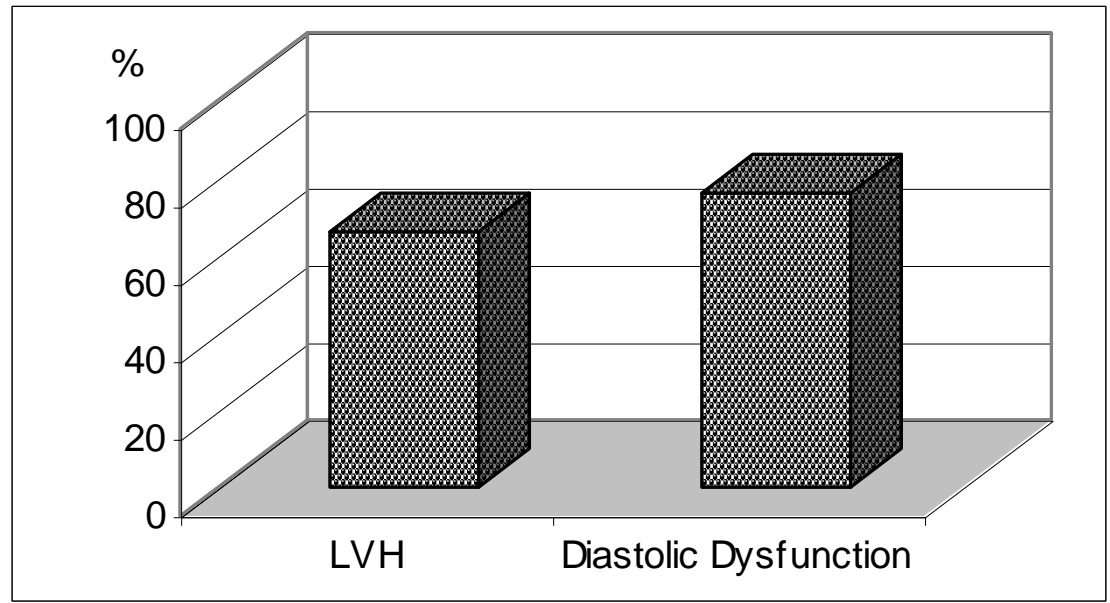




\section{Discussion}

The prevalence rate of ESRD during 2005 is 260 PMP, While it was 250 PMP during the year 2002 (El Minshawy et al., 2002) and 225 PMP allover Egypt (Afifi and Abd El Kraim, 1999) in Brazil it is 390 PMP (Oliveira et al., 2005) and in Yemen it is 320 PMP (Al-Rohani, 2004). In England the prevalence of RRT increased from 175 PMP in 1982 to 626 PMP in 2002 (Feest et al., 2005) In Sweden the prevalence of patients om dialysis and transplantation being approximately 750 PMP (Schon et al., 2004) The difference in prevalence rate between different countries is attributed to many factors and a higher prevalence rate correlates positively with gross national products (Brunner et al., 1989)

The low rate of performing renal biopsy for patients before ESRD $2.6 \%$ reflects the need for changing education and training programs for nephrologits to early detection and mangement of renal diseases that may be complicated with renal failure.

The results of the present study illustrated that the etiology of ESRD was unknown in $28 \%$ of cases. Previous report by (El Minshawy et al., 2002) reported that unknown etiology of ESRD in El Minia Governorate during the year 2002 was 32.9 $\%$ these high figures may be due to lack of awarness of the treating physcians about the proper time of refering patients to nephrology centers as they refer the patients after their uremic state becomes very advanced.

This is in agreement with (Frassinetti et al., 2000) who found that $24 \%$ of his patients with uncertain etiology. Avoran et al., 2002 concluded that for patients with long standing renal disease, earlier consultation with nephrologist is associated with lower mortality in the first year of dialysis, similarly Stack, 2003 concluded that late nephrology referral is associated with greater death risk in new patients of ESRD and more frequent pre ESRD care can increase survival benefits.

In this study hypertensive nephrosclerosis was responsible for $20.7 \%$ of cases of ESRD in El Minia Governorate durin the year 2005 while it was responsible for 16.5 of cases of ESRD in El Minia governorate during the year 2002 (El Minshawy et al., 2002). Similarly (Afifi and Abd El Kraim, 1999) reported that hypertension is responsible for $29.7 \%$ of cases of ESRD in Cairo, $28.9 \%$ in lower Egypt governorates, $25 \%$ in upper Egypt governorate, $27.3 \%$ in Suez Canal governorate, $26.5 \%$ in border governorates. However (Frassinetti, et al., $2000)^{14}$ found that hypertension constitute only $10 \%$ of causes of ESRD in black patients.

(Lea and Nicholas 2002) reported that hypertension and diabetes mellitus are the key risk factor for kidney disease which are both becoming prevalent in USA.

Obstructive uropathy as a cause of ESRD in El Minia governorate is $12.7 \%$ while it was $9.6 \%$ during the year 2002 (El Minshawy et al., 2002). Obstructive uropathy due to schistosomiasis (caused by schistosoma hematobium) is $4.4 \%$ while it was responsible for $7.2 \%$ of ESRD during the year 2002 One explanation of the decreasing prevalence of the urinary schistosomiasis (transmitted via the snail bulinus truncatus) is the success in the preventive programs against shistosomiasis carried out by Ministry of health, therfore these programs should be continued.

(Afifi and Abd El Kraim, 1999) reported that shistosomal obstructive uropathy is responsible for ESRD by $3.9 \%$ in Cairo, $6.6 \%$ in lower Egypt governorates, zero \% in Canal governorates and $1.5 \%$ in border line governorates.

Resukts of the current study illustrated that chronic glomerulonephritis constitute $10.4 \%$ of causes of ESRD in El Minia governorate while it was $6 \%$ during the year 2002 but (Frassinetti, et al., 2000) found that glomerulonephritis is responsible for $20 \%$ of ESRD in the black patients. This discrepincy between the two results may be due to that his study was concerned with black population only.

Diabetic nephropathy is responsible for only $5 \%$ of causes of ESRD in $\mathrm{El}$ Minia governorate while it was $8.4 \%$ 
during the year 2002. (Afifi and Abd El kraim 1999) reported that it is responsible for $12.5 \%$ in Cairo, $6.4 \%$ in lower Egypt governorates $5.2 \%$ in upper Egypt governorates, $10.7 \%$ in Canal governorates, 11.8 $\%$ in border line governorates. (Coresh et al., 2003) reported that hypertension and diabetes Mellitus are a key predictor of CKD. (Letourneau et al., 2003) found that in $37 \%$ of elderly patients on HD were diabetics.(Frassinetti, et al.,2000) reported that diabetic nephropathy is responsible for $38 \%$ of ESRD. We belive that the cause of low rate of diabetic nephropathy as a cause of ESRD in El Minia Governorate is due to that the Diabetic patients die from other complications of diabetes Mellitus before they develop ESRD

Fifty six percent of the patients are living in rural areas whereas $44 \%$ are urban residents Males constituted $64 \%$ while females were $36 \%$ of the dialysis patients while during the year 2002 patients who were living in rural areas constituted $74.6 \%$ and those who were living in urban area constituted $25.4 \%$ males constituted $62.9 \%$ while females were $37.1 \%$.

(Cass et al., 2001) reported that ESRD incidence among indigeous Australian is high in remote regions where it is up to 30 times the national incidence for all Australians. In urban regions the incidence is much lower but remains significantly higher than the national incidence. Forty eight percent of indigenous ESRD patients come from regions without dialysis or transplant facilities and $16.3 \%$ from regions with satell dialysis facilities, (Brameld et al., 1999) found that rates of renal failure were 15 times greater in aboriginal population than non aborigines.

Results of the current study illustrated that hypertension is highly prevelant among HD patients $50 \%$ this is in agreement with (Vukusich et al., 2002) who concluded that hypertension is highly prevalent among HD patients but they do not determine if it is the cause of ESRD or not. Also (Otero et al., 2005) reported that prevalence of hypertension as a risk factor for cardiovascular disease was $31.5 \%$. and (Portoles et $a l ., 2005)$ who found that the prevalence of hypertension in hemodialysis patients was $75.8 \%$

Our results illustrate that left ventricular hypertrophy and diastolic dysfunction were prevalent among HD patients 66 $\%$ and $76 \%$ respectively this is in agreement with (Birchem et al., 2005) who reported that hypertension in hemodialysis patients is a risk factor for left ventricular hypertrophy, diastolic dysfunction and congestive heart failure, good blood pressure control may promote its regression we found that the prevalence of dyslipedemia is $21 \%$ in hemodialysis patients only $30 \%$ of them under tratment of dyslipedemia with drug therapy (Portoles et al., 2005) found the prevalence of dyslipedemia $34.1 \%$ in hemodialysis patients only $69.5 \%$ of them under drug therapy. Similarly (Otero et al., 2005 ) reported that the prevalence of dyslipedemia is $21.9 \%$

The mean age of ESRD patients was $44.6 \pm 13.7$ years. The mean age of ESRD patients in El Minia governorate is lower than that of latin Amreican countries which is 50.5 \pm 10.9 years (Mazzuchhi et al., 1997) the younger the age the more the social problems as these patients are in the productive and creative peroid of life

For the treatment of anemia $50 \%$ of patients received blood transfusion while only $14 \%$ received erythropoeitin the low number of patients trated by erythropoeitin is related to its cost

HbsAg was postive in $3.5 \%$ and did not correlate with blood transfusion. On the other hand $\mathrm{HCV}$ antibodies were positive in $52 \%$ and significantly correlated with blood transfusion $(p<0.05)$. The high prevalence of HCV antibodies has drawn attention for better control of blood screening and the need to increse iron and erythropoetin among dialysis patients insteated of blood transfusion.

The rate of renal transplantation is 13/1000 dialysis patients / year. All kidneys came from living donors. This rate is lower than other Egyptian governorates which is 32/1000 dialysis patients /year (Afifi and Abd El Karim, 1999)

The low transplantation rate is due to absence of specialized transplantation 
centers in El Minia governorate and those patients who treated by renal transplantation are treated in in specialized centers in the other governorate although they are inhabitant in El Minia Governorate Attempts to estabish a program for renal transplantation in El Minia governorate are undergoing although facing many obstacles.

The number of deaths among HD patients in 2005 is $210 / 1000$ dialysis patients in order to accurately calculate the mortality rate, follow up surveys overcoming years are needed.

In our study causes of death were 53 $\%$ due to cardiovascular diseases and $14 \%$ were due to cerebrovascular accidents these results were similar to the results of (Kessler, 2002) who found that cardiovascular disease is the leading cause of death in patients with ESRD and cardiovascular mortality is 10 - 30 fold higher in ESRF patients than the general population.

Also our results are in agreement with (McDonald et al., 2002) who found that cardiac and infective causes are the predominant causes of death among dialysis patients and (Bellorin et al., 2002) who reported that cardiovascular causes are the primary causes of death $(39.5 \%)$ of $\mathrm{HD}$ patients in Venezuela.

\section{Recommendations}

Education program for Nephrologists and practitioners should be strengthened with special emphasis on etiological factors leading to ESRD , blood pressure control with focus on systolic pressure appears to be an important stratgey to improve outcomes in HD patients, Attempts to establish a program for renal Transplantation should be encourged.

\section{References}

1. Afifi A, and Abdel Karim (1999): Renal replacement therapy in Egypt; The first Annual Report Of The Egyptian Society Of Nephrology (1996). East Mediterranean Health Journal Vol.5 No.5 1023 - 1029

2. Al-Rohani M. (2004): Renal failure in Yemen Transplant Proc. Jul-Aug; 36 (6): $1777-9$
3. Avoran J, Bohn RL, Levy E, Levin R, Owen WF Jr, Winkelmayer .WC, and Glynn RJ.(2002): Nephrologist care and mortality in patients with chronic renal insufficiency Arch Intern Med 23, 162(17) 2002-6

4. Barsoum RS. (2003): End stage renal disease In North Africa . Kidney Int. Suppl. Feb. (83) S111 - 4

5. Bellorin FE, Milanes CL, Rodriguez IB.(2002): End stage renal disease and its treatment in Venezuela. Artif Organs 26(9):747-9

6. Birchem JA, Fraley MA, Senkottaiyan N, Alpert MA. (2005): influence of hypertension on cardiovascular outcomes in hemodialysis patients. Semin Dial 18(5) $391-5$

7. Brameld K, Holman D, Thomas M, and Bass J. (1999): Use of state data bank to measure incidence and prevalence of chronic disease end stage renal failure Am J Kidney Dis.

8. Brunner FP, Wing AJ, Dykes SR.(1989): International review of renal replacement therapy: strategies and results. In Maher JF ed. Replacement of renal function by dialysis, Kluwer Dordrecht: 697 - 719

9. Cass A, Cunningham J, Wang $\mathbf{Z}$, and Hoy W. (2001): Regional variation in the incidence of end stage renal disease in indigenous Australians Med J Aust 2; 175(1) $24-7$

10. Coresh J, Astor B, Sarnak MJ. (2004): Evidence for increased cardiovascular dusease risk in patients with chronic kidney disease.Curr Opin Nephrol Hypertense. Jan (1) $73-81$

11. Coresh J, Astor BC, and Eknoyan G. (2003): Prevalence of chronic kidney disease and decreased kidney function in the adult Us population: national health and nutrition examination survey. Am J Kidney Dis 41(1) 1-12

12. El Minshawy O, El Sharqawy M, and Ewis A (2002): End stage renal disease in El Minia Governorate (Central Egypt): An epidemiological Study JESN., 4(1) Dec. 34 $-41$

13. Feest TG, Rajamahesh J, Byrne C, Ahmad A, Ansell D, Burden R, and Roderick PJ. (2005): Trends in adult renal replacement therapy in the UK: 1982-2002 QJM Jan;98(1)21 - 8

14. Frassinetti FP, Ellis PA, Roderick PJ, Cirns HS, Hicks JA, and .Cameron. JS. (2000): Causes of end stage renal failure in black patients Am J Kidney Dis 36(2): 301 $-9$ 
15. Kan CD, Yang YJ. (2004): Coronary artery bypass grafting in patients with dialysis dependent renal failure. Tex Heart Ins J. 31(3) $224-30$

16. Kessler M. (2002): Cardiovascular disease in terminal end stage renal failure epidemilogical aspects Nephrologie 23(7): 361-5

17. Lea Jp, and Nicholas SB. (2002): Diabetes Mellitus and hypertension : key risk factors for kidney disease $\mathrm{J}$ Nail Med Assoc 94(8S)7S-15S

18. Letourneau I, Ouimet D, Dumont $M$, Pichette V, and Leblanc . M.(2003): Renal replacement therapy in End Stage Renal Disease patients. Am J Nephrol 23(2)71-7

19. Mazzuchi N, Schwedt E, Fernandez JM. (1997): Latin American registry of dialysis and renal transplantation: annual dialysis data report. Nephrol Dial Transplant 12: $2521-2527$

20. McDonald SP, Russ GR, Kerr PG, Collins JF, Australia and New Zealand Dialysis and transplant Registry.(2002): ESRD in Australia and New Zealand at the millenium: a report from the ANZDATA registry Am J Kidney Dis. 40(6) 1337-9

21. Oliveira MB, Romao JE, and Zatz R. (2005): End stage renal disease in Brazil: epidemiology, prevention and treatment. Kidney Int. Supp. Aug; (97): S82 - 6

22. Otero A, Abelleira A, Gayoso P. (2005): Occult chronic kidney (OCKD), and cardiovascular risk factors. Epidemiologic study. Nephrologia 25(3) $275-87$

23. Portoles J, Lopez-Gomez JM, Aljama P. (2005): Cardiovascular risk in hemodialysis in Spain: Prevalence, management and target results (MAR study) Nephrologia 25(3)297- 306

24. Schon S, Ekberg H, Wikstorm B, Oden A, Ahlmen J. (2004): Renal Replacment therapy in Sweden Scand J Urol Nephrol. 38(4):332 - 9

25. Stack AG. (2003): Impact of timing of nephrology referal and pre-ESRD on mortality risk among new ESRD patients in the untd statesAm J Kidney Dis.41(2)310-8

26. Stako SG, Freedman BI, Moossavi S. (2005): Genetic factor in end stage renal disease. Kidney Int. Suppl. Apr.(94) S46- 9

27. Stewart GA, Gansevoort RT, Mark PB, Rooney E, McDonagh TA, Dargie HJ, Stuart R, Rodger C, Jardine AG. (2004): Electrocardiographic abnormalities and uremic cardiomaopathy. Kidney Int. Jan. 67(1) $217-26$

28. Vukusich A, Fierro A, Morales J, Fantuzz A, Vukusich C, Manalich . J, and Zehnder C. (2002): Epidemiology of hypertension in chronic hemodialysis Rev Med Chil 130 (6): 610 - 5

29. Weiner DE, SarnakMj. (2004): Managing dyslipedemia in chronic kidney disaese $\mathbf{J}$ Gen Intern Med. 19(10) 1045 - 52 


\section{العلاج الإحلالى للفشل الكلوى وزيادة مخاطر الإصابة

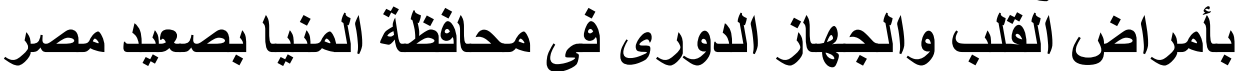

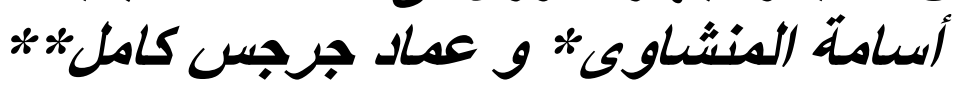

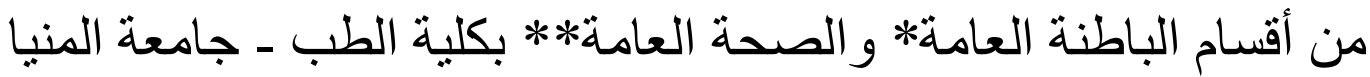

تقع محافظة المنيا فى صعيد مصر ويسكنها حو الى 4.6 مليون نسمة موز عين في 9

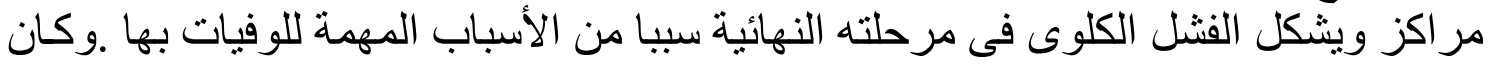

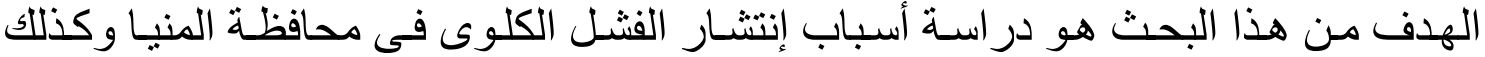

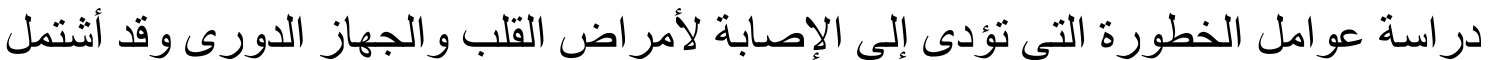

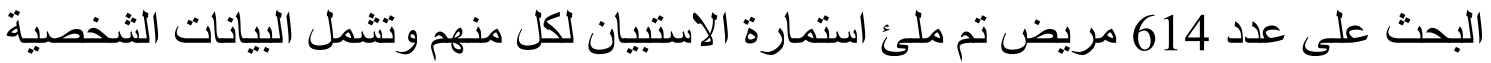

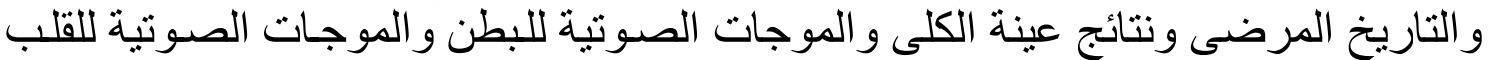

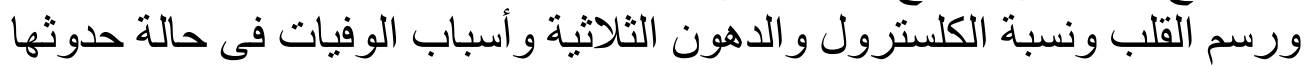
وجاءت نتائج البحث كالأتى ورنى

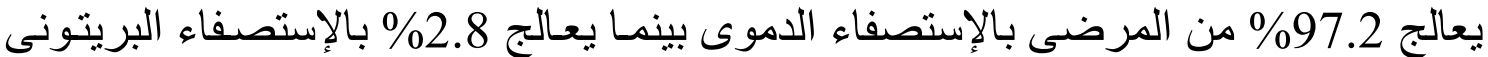
أو زرع الكلى وكانت أسباب الفشل الكلوى فى مرحلته النهائية كالأتى :-

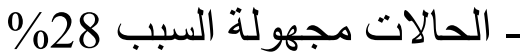
- إرتفاع ضغط الدم 20.7 - إنسداد مجرى الحالبين 12.7

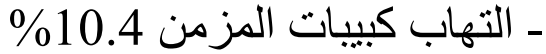

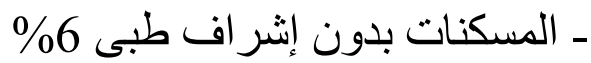

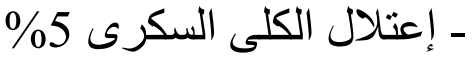

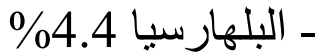

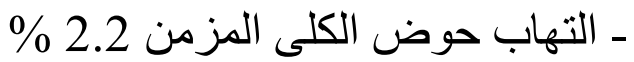

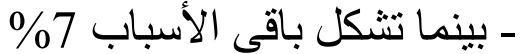

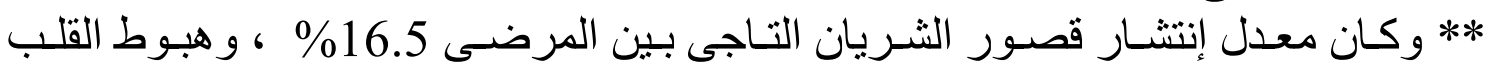
الإحتقانى 28\% وكان معدل حدوث الوفيات بين مرضى الإستصفاء الدئ الدموى 210 / 21000

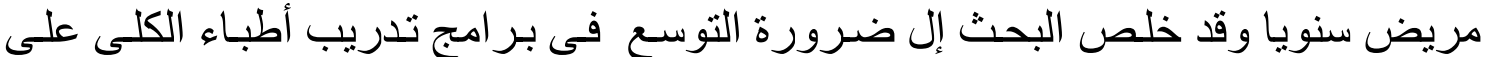

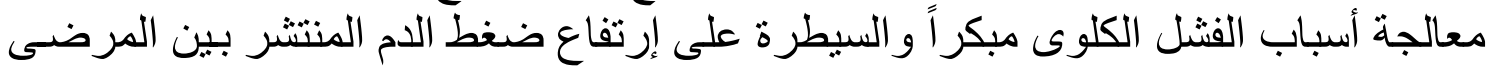

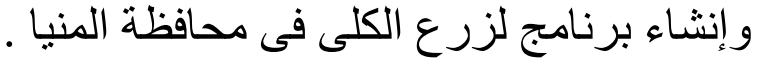

